\title{
Nonlinearity Compensation through Optical Phase Conjugation for Improved Transmission Reach/Rate
}

Da Ros, Francesco; Yankov, Metodi Plamenov; da Silva, Edson P.; Lillieholm, Mads; Kaminski, Pawel Marcin; Guan, Pengyu; Hu, Hao; Clausen, Anders T.; Galili, Michael; Oxenløwe, Leif Katsuo

\section{Published in:}

Proceedings of 2018 20th International Conference on Transparent Optical Networks

Link to article, DOI:

10.1109/ICTON.2018.8473621

Publication date:

2018

Document Version

Peer reviewed version

Link back to DTU Orbit

Citation (APA):

Da Ros, F., Yankov, M. P., da Silva, E. P., Lillieholm, M., Kaminski, P. M., Guan, P., Hu, H., Clausen, A. T., Galili, M., \& Oxenløwe, L. K. (2018). Nonlinearity Compensation through Optical Phase Conjugation for Improved Transmission Reach/Rate. In Proceedings of 2018 20th International Conference on Transparent Optical Networks (pp. 2 pp.). IEEE. https://doi.org/10.1109/ICTON.2018.8473621

\section{General rights}

Copyright and moral rights for the publications made accessible in the public portal are retained by the authors and/or other copyright owners and it is a condition of accessing publications that users recognise and abide by the legal requirements associated with these rights.

- Users may download and print one copy of any publication from the public portal for the purpose of private study or research.

- You may not further distribute the material or use it for any profit-making activity or commercial gain

- You may freely distribute the URL identifying the publication in the public portal 


\title{
Nonlinearity compensation through optical phase conjugation for improved transmission reach/rate
}

\author{
Francesco Da Ros ${ }^{1}$, Metodi P. Yankov ${ }^{1,2}$, Edson P. da Silva1, Mads Lillieholm ${ }^{1}$, Pawel M. Kaminski', \\ P. Guan' ${ }^{1}$, Hao Hu${ }^{1}$, Anders T. Clausen ${ }^{1}$, Michael Galili' ${ }^{1}$, and Leif K. Oxenløwe ${ }^{1}$ \\ ${ }^{1}$ DTU Fotonik, Technical University of Denmark, DK-2800 Kongens Lyngby, Denmark, fdro@fotonik.dtu.dk \\ ${ }^{2}$ Fingerprint Cards ApS, Lyskar 3CD, 2730 Herlev, Denmark
}

\begin{abstract}
Optical phase conjugation is a well-known technique to provide dispersion and nonlinearity compensation directly in the optical domain. The link properties play an important role in the achievable improvements in transmission reach/rate. Here, we review our recent investigations on the impact of sub-optimum transmission links as well as our effort on the implementation of the optical phase conjugator itself looking beyond using highly nonlinear fibers as nonlinear medium and focusing on integrated silicon waveguides. Preliminary results on combining optical phase conjugation with digital techniques such as probabilistic shaping will also be discussed.
\end{abstract}

Keywords: optical communication, nonlinearity compensation, four-wave mixing, optical phase conjugation.

\section{INTRODUCTION}

Signal distortion caused by nonlinearity during transmission is one of the key challenges that must be addressed in order to provide the increase in data rates required by the ever-growing demand for high-speed connectivity. Several nonlinearity mitigation and compensation techniques have been proposed and investigated throughout the recent years [1], focusing on either the digital [1-3] or the optical [4-17] domain. While digital nonlinearity compensation through digital backpropagation can effectively erase the distortion caused by intra-channel nonlinearity [2], the available receiver bandwidth prevents it from compensating for inter-channel effects by using practical receivers. Alternatively, inter-channel effects can be compensated for by using all-optical approaches such as optical phase conjugation (OPC) which potentially enables full-band nonlinearity compensation [2]. OPC has been re-discovered in the past few years with several impressive demonstrations being reported [4-10], however a number of challenges still need to be addressed.

In this talk, we review our recent efforts on investigating the impact of link non-ideality on the nonlinearity compensation provided by practical implementations of OPC, caused by e.g. the inherent wavelength shift introduced by four-wave mixing-based OPC [11, 12] and sub-optimum positioning of the OPC within the link [13]. Additionally, the potential for joint digital and optical compensation by combining OPC with the powerful probabilistic shaping (PS) will be discussed [14]. Finally, we will touch upon the use of nonlinear material for OPC beyond the more commonly used highly nonlinear fibers (HNLFs) [2-6, 8-13] and periodically poled lithium niobate (PPLN) [8], by reviewing our recent results on OPC using silicon waveguides [15-17].

\section{ACKNOWLEDGEMENTS}

This work was supported by the DNRF Research Centre of Excellence, SPOC (ref. DNRF123) and the DFF project NANO-SPECs (DFF-4005-00558B).

\section{REFERENCES}

[1] A.D. Ellis, et al., "Performance limits in optical communications due to fiber nonlinearity," Advances in Optics and Photonics 9(3), 429-503 (2017).

[2] I. Sackey, et al., "Kerr nonlinearity mitigation: mid-link spectral inversion versus digital backpropagation in 5x28-GBd PDM 16-QAM signal transmission," Journal of Lightwave Technology 33(9), 1821-1827 (2015).

[3] E.P. da Silva, et al., "FEC-assisted Perturbation-based Nonlinear Compensation for WDM Systems" in Proc. OFC 2018, paper W3A.3.

[4] A.D. Ellis, et al., "4 Tb/s transmission reach enhancement using $10 \times 400 \mathrm{~Gb} / \mathrm{s}$ super-channels and polarization insensitive dual band optical phase conjugation," Journal of Lightwave Technology 34(8), 1717-1723 (2016).

[5] I. Sackey, et al., "Kerr nonlinearity mitigation in 5×28-GBd PDM 16-QAM signal transmission over a dispersion-uncompensated link with backward-pumped distributed Raman amplification," Optics Express 22(22), 27381-27391 (2014).

[6] F. Da Ros, et al., "Kerr nonlinearity compensation in a 5× 28-GBd PDM 16-QAM WDM system using fiber-based optical phase conjugation," in Proc. of ECOC 2014, paper P. 5.3. 
[7] K. Solis-Trapala, et al., "Nearly-ideal optical phase conjugation based nonlinear compensation system," in Proc. of OFC 2014, paper W3.F.8.

[8] T. Umeki, et al., "Simultaneous nonlinearity mitigation in $92 \times 180$-Gbit/s PDM-16QAM transmission over 3840 km using PPLN-based guard-band-less optical phase conjugation," Optics Express 24(15), 16945-16951 (2016).

[9] Y. Sun, et al., "Optical nonlinearity mitigation of $6 \times 10 \mathrm{GBd}$ polarization-division multiplexing 16-QAM signals in a field-installed transmission link," in Proc. OFC 2017, paper Th.3.J.2.

[10] H. Hu, et al., "Fiber nonlinearity mitigation of WDM-PDM QPSK/16-QAM signals using fiber-optic parametric amplifiers based multiple optical phase conjugations," Optics Express 25(3), 1618-1628 (2017).

[11] I. Sackey, et al., "Waveband-Shift Free Optical Phase Conjugator for Spectrally Efficient Fiber Nonlinearity Mitigation,” Journal of Lightwave Technology, 36(6), 1309--1317 (2018)

[12] F. Da Ros, et al., "Impact of signal-conjugate wavelength shift on optical phase conjugation-based transmission of QAM signals," in Proc. of ECOC 2017, paper P1.SC4.66.

[13] F. Da Ros, et al., "Link-Placement Characterization of Optical Phase Conjugation for Nonlinearity Compensation," in Proc. of OFC 2018, paper W3E.3.

[14] M.P. Yankov, et al., "Experimental Comparison of Probabilistic Shaping with online PMF Optimization and Mid-link OPC," in Proc. of CLEO 2018, paper STu4C.2.

[15] D. Vukovic, et al., "Multichannel nonlinear distortion compensation using optical phase conjugation in a silicon nanowire," Opt. Expr. 23(3), 3640-3646 (2015).

[16] A. Gajda, et al., "Silicon Waveguide with Lateral p-i-n Diode for Nonlinearity Compensation by On-Chip Optical Phase Conjugation ion," in Proc. of OFC 2018, paper W3E.4.

[17] F. Da Ros, et al., "Nonlinearity Compensation for Dual-Polarization signals using Optical Phase Conjugation in a Silicon Waveguide," in Proc. of CLEO 2018, paper STu4C.1. 